\title{
MULTIPLE CASES OF ERYTHEMA NODOSUM IN A CLASS OF SCHOOL GHILDREN
}

BY

ALBIN LANDAU, M.D.

(From the Children's Hospital, Gothenburg, Sweden.)

It is widely, though not universally, accepted that most cases of erythema nodosum in children are connected with tuberculous infection. The frequency of positive tuberculin reactions in children with erythema nodosum almost reaches one hundred per cent. Patients who do not react positively to tuberculin, even in high doses, are insignificant in number: in Dr. Wallgren's statistics here about two per cent.

The characteristic moment for the appearance of erythema nodosum in tuberculous infections is the end of the incubation period, when the organism is in an allergic condition; erythema nodosum is a parallergic phenomenon. This circumstance explains the cases in which erythema nodosum appears during the later stage of a tuberculous disease in connection with the measles, whooping-cough, and other illnesses that may produce a passing decrease in allergy; with the ensuing return of allergy, erythema nodosum may sometimes appear.

As erythema nodosum appears at the close of the incubation period of tuberculosis, when the children become sensitive to tuberculin, an attempt should be made in these cases to discover visible manifestations of the tuberculous process, which are to be found in most cases in the form of hilum gland infiltrations, demonstrable by $\mathrm{X}$-rays. Erythema nodosum in children is thus most often a significant symptom suggesting that we are confronted by a recent tuberculous process which must be the object of critical investigation, whether it calls for medical treatment or not. On this point Wallgren expresses the opinion that most children with erythema nodosum, especially before the school age, require careful medical inspection and supervision. It is not the erythema nodosum, but the tuberculous process unmasked by it, that must be treated. The time and nature of the treatment depends on the degree of this affection.

A no less important proceeding which the discovery of a fresh tuberculous process should initiate, is the tracing of the source of infection. In cases where the tuberculous infection first appears as erythema nodosum, the task is in so far facilitated that we can more easily determine the approximate date of infection, for erythema nodosum usually shows itself, as we have mentioned, at the end of the incubation stage, and the incubation period for 
tuberculosis is held to be from 3 to 7 weeks. By careful enquiries, dispensary visits in the home, etc., we can succeed in many cases, no doubt, in tracing the source of infection and in taking the necessary steps.

It not rarely happens, however, that infectious consumptives have already caused little endemics of erythema nodosum or tuberculous infections before we have succeeded in tracing them. Such endemics have been described when occurring among children of the same family (Appert ${ }^{1}$, Gendron $^{5}$, Symes ${ }^{10}$, Wallgren ${ }^{12}$ and others), among children in a children's home, in hospital wards, among the inhabitants of small towns (Symes, Wiborg ${ }^{13}$, etc.), among children in the same building (Belfrage $\left.{ }^{2}\right)$, and in schools (Landau ${ }^{6}$, Lundius ${ }^{7}$, Wallgren). A number of authors, with the support of such epidemic appearances of erythema nodosum, consider that it is a manifestation of an acute specific infectious disease (Comby ${ }^{3}, \mathrm{Feer}^{4}$, Tachau $^{11}$, Symes ${ }^{10}$ ). As against this view Wallgren emphasizes that in all the six family endemics observed by him, as well as in a school endemic, he has after careful investigation found a tuberculous source of infection, and he assumes that the same must be the case with the other epidemics observed. T'his was also the case both with the house endemic cibserved by Belfrage, and with the school class infection described by the present writer in 1930 . Further carefully investigated cases which throw light on this question may therefore be of interest, and I am able to report of an additional school-class endemic of erythema nodosum observed in Gothenburg.

On March 28th, 1931, a girl of 11 was admitted to the children's hospital from one of the Gothenburg primary schools, for erythema nodosum. In compiling the medical report $I$ made investigations into a possible tuberculous source of infection in the home or among her acquaintances, but none was known. Nor did the patient know of any girl at school who coughed much or had been ill, but when asked point-blank if any other girl in her class had had red spots on the lower extremities of late, she stated that three other girls in the same class had been affected by them at the same time.

All four girls were admitted to the children's hospital, and showed fresh outbreaks of erythema nodosum as well as fresh hilum gland enlargements in the skiagrams.

No suspicious source of infection could be designated, but as there was reason to presume that it could be found in the class, a thorough examination was undertaken of all the members of the class, as well as of the three teachers who did duty there.

The three teachers showed no symptoms of pulmonary tuberculosis, either physically or by X-rays.

The class consisted of 31 girls of 11-12 years of age, who were all tested with tuberculin and examined physically and radiologically. The result was that 29 girls (93.6 per cent.) reacted positively to tuberculin, while only two were negative, even with a Mantoux test up to $3 \mathrm{mgrm}$. Of the 29 tuberculin-positive girls, one revealed a right-sided cavernous pulmonary tuberculosis, and after repeated tests she showed sparse tuberculous bacilli in her sputum. The general condition of this girl was excellent, free from fever; she was the stoutest in the class, and gave no impression of suffering from active tuberculosis.

Besides the four girls with erythema nodosum (Fig. 1), one of whom afterwards had pleurisy, four of the other girls showed increased sedimentation reaction and by X-rays fresh hilum gland enlargements of such dimensions that all of them were judged to require lengthy hospital treatment. Four more girls had hilum gland 
enlargements of uncertain age, the other tuberculin-positive children had probably older infections, four of them showing calcified hilum shadows (Table 1).

TABLE I.

Analysis of class of 31 schoolgirls including 4 cases of erythema nodosum.

\begin{tabular}{|c|c|c|c|c|c|c|}
\hline $\begin{array}{l}\text { Tuberculin } \\
\text { reaction. }\end{array}$ & \multicolumn{4}{|c|}{ Disease. } & $\begin{array}{l}\text { No. of } \\
\text { cases. }\end{array}$ & Per cent. \\
\hline Positive & Pulmonary tuberculosis & $\ldots$ & $\cdots \quad \ldots$ & $\ldots$ & 1 & \\
\hline , & Erythema nodosum & $\ldots$ & $\cdots \quad \cdots$ & $\cdots$ & 4 & \\
\hline,, & Tuberculous bronchial g & inds: & fresh casez & $\ldots$ & 4 & 03.6 \\
\hline , & , & , & uncertain age & $\cdots$ & 4 & 800 \\
\hline , & , & , & older cases & $\cdots$ & 12 & \\
\hline , & , $\quad$, & , , & with calcified & foci & 4 & \\
\hline Negative & & & & & 2 & $6 \cdot 7$ \\
\hline & & & Total & $\ldots$ & 31 & \\
\hline
\end{tabular}

\section{Discussion.}

In a school class of 31 girls of ages from 11 to $12,93 \cdot 6$ per cent. showed evidence of tuberculous infection, which is, of course, a remarkably high proportion. In the northern countries we can expect not more than 50 per cent. of children of that age in primary schools to be infected. The high figure in the present school-class is explained by the discovery of the girl with pulmonary tuberculosis, who must have been the source of infection to a good proportion of the infected class-mates. This supposition is supported by at least 8 fresh cases of tuberculosis, 4 of which began with erythema nodosum.

Of great interest is the simultaneous appearance of erythema nodosum in the 4 girls. In view of the usual appearance of this condition at the close of the incubation time for tuberculosis, there is reason to assume here that the girls had been infected one or two months earlier, and that the infection must have taken place at about the same time in all the cases. There is also a plausible explanation of this, for the form mistress states that the girl with pulmonary tuberculosis, who has not been away from school for a single day all the term, had had a ' cold' for a short period at the end of February, i.e., 4 to 6 weeks before the erythema nodosum cases occurred, and had coughed so much that the teacher had advised her to keep away from school, which the girl had not done. She soon got better, however, and shook off her cough. 
In all probability this girl, who has a pulmonary tuberculosis with sparse secretion of bacilli, and who had perhaps for the most part not been dangerous for those around her, contracted on one occasion towards the end of February an acute infection with bronchitis and violent coughing, which had stimulated the excretion of bacilli and made her very infectious. This had resulted in an epidemic of erythema nodosum in four, and of fresh hilum tuberculosis in eight, of her class mates. Whether some of the other tuberculin-positive children had been previously infected by this girl is impossible to decide. That her infectiousness was restricted to a short space of time is supported by the consideration that the two girls who were tuberculin-negative six weeks after this period (when the erythema nodosum appeared), did not react to tuberculin even two months later (after the

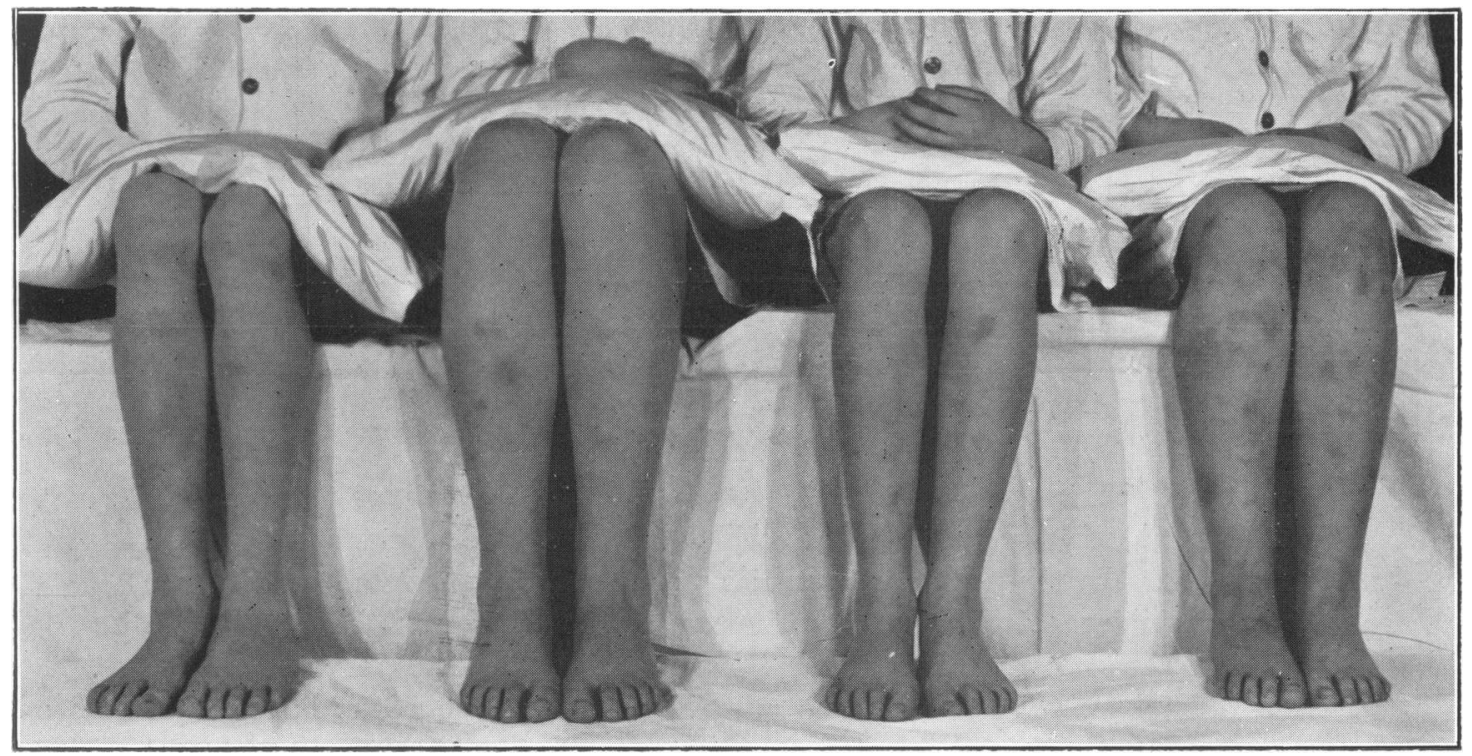

Fig. 1. Four of the girls in the class with simultaneous eruptions of erythema nodosum.

source of infection had been removed). It is also to be noted that one of these girls did not join the class until the 5th of March, which may explain her freedom from infection with tuberculosis. If this is so, there remains only one girl out of 29 in the class that had escaped tuberculosis in spite of the possibility of infection from her school-mate.

The present observations not only give further support to the interpretation of erythema nodosum as an early symptom of tuberculosis in children, and throws light on its importance as a diagnostic aid, but also emphasizes the importance of tracing the source of the tuberculous infection, with all its consequences. Thus, in the present instance the presence of erythema nodosum led, after persistent search, to the discovery of an individual with pulmonary tuberculosis, her segregation from an infectionthreatened centre (the school), her proper care and treatment, and the 
discovery of fresh hilum-gland tuberculosis in eight girls who were consequently let off the strain of school work, to enjoy a much required rest during the first phase of such a serious disease.

In the epidemic of erythema nodosum in one of the primary school classes in 1927, as recorded by Wallgren, all 33 of the girls were exposed to tuberculous infection from a class-mate with pulmonary tuberculosis, and reacted positively to tuberculin; 12 of these developed erythema nodosum and 6 had a period of fever from an unknown cause, all during one and the same term. In 13 of the cases there were hilum-gland affections radiologically demonstrable. The rest had what were probably tuberculous infections of older date.

In 1930 I gave an account of a tuberculous infection in a primary school class at Gothenburg. In a girl of 12, who visited the children's hospital's out-patient department, I found pulmonary tuberculosis with tubercle bacilli in the sputum. In taking down the history of the case I discovered, from questions put to the patient, that 2 , possibly 3 , of the girls in the class had had erythema nodosum that term, and on a consequent examination of the class I found 25 out of the 30 girls (or 83.4 per cent.) were infected with tuberculosis, and of these, apart from the girls with erythema nodosum, 8 showed fresh hilum-gland affections on X-ray examination.

We may now compare the circumstances surrounding these three epidemics. The numerous cases of erythema nodosum in Wallgren's class led to the whole class being examined, and to the discovery of a girl with pulmonary tuberculosis as the suspected source. In my first epidemic, the discovery of the tuberculous gịrl induced me to question the patient directly about secondary cases, not only in her home but also at school, with the consequent discovery of the cases in the class. In the epidemic now recorded, a direct inquiry was also made about other cases of erythema nodosum in the class, with a subsequent search for the source of infection, which was only discovered after careful and persistent investigation. None of the girls could be at first sight suspected, and the girl with pulmonary tuberculosis was the last of those examined.

The facts of these three epidemics clearly point to the importance of an exact anamnesis and a search for secondary or primary cases when in the presence of erythema nodosum or tuberculosis in children. They also show that, when dealing with children in the school age, we must not forget to look into the state of things in the class or in the school, on which occasions the staff must not be left out of count should further investigations be pursued.

Another point worth discussing in this connexion is that of the infectiousness of children with bronchial-gland tuberculosis, i.e., not pulmonary tuberculosis proper. Since, : by means of irrigation of the stomach and guinea-pig tests, we have now succeeded in finding tubercle bacilli in children with fresh hilum-gland tuberculosis $\left(\mathrm{Opitz}^{8}\right.$, V. Poulsen ${ }^{9}$, 
Wallgren and others), and in some of those with erythema nodosum (Wallgren), this question of the degree of infectiousness is an important one. Proposals have been made to assess the danger of infection according to a certain number of negative tests, but this is an uncertain and capricious proceeding. Theoretically there is, of course, risk of infection, but in practice it is only in a few cases that it has been possible to show proof of a child, with hilum-gland tuberculosis only, having infected another child. According to our experience at the Gothenburg Children's Hospital, we have succeeded in the great majority of cases of hilum tuberculosis in tracing the sources of infection to real cases of pulmonary tuberculosis. The question is, however, of extreme importance, and this has induced me to report at length the circumstances of the three above-mentioned endemics. In all three cases there were sources of infection which had actual pulmonary tuberculosis with cavitation. In the last endemic I thought at first that I should have to be content merely with a suspicion of one of the children with hilum tuberculosis, but finally I found the girl with pulmonary tuberculosis. In the endemics described by me no new infections appeared in the period immediately following the removal of the infectious girl, but I would point out that most of the girls with fresh hilum-gland affections, at the last endemic at least, were segregated at the same time.

I do not cite these cases merely as evidence against the infectiousness of hilum tuberculosis, but to emphasize that in practice, when tracing a source of infection, we should not rest content with a hilum tuberculosis only as the possible cause of other cases of infection.

\section{REFERENCES.}

1. Appert. ref. Wallgren (see below).

2. Belfrage, H., Acta Pædiat., Stockholm, (in the press).

3. Comby, Arch. de méd. d. enf., Paris, 1923, XXVI, 329.

4. Feer, Schweiz. med. Wchnschr., Basle, 1926.

5. Gendron, Bull. et. mém. Soc. méd. des Hôp., Paris, 1920, 475.

6. Landau, A., Münch. med. Wchnschr., Munich, 1931, LXXVII, 1663.

7. Lundius, Acta tuberc. Scandinav., Copenhagen, 1929, IV.

8. Opitz, Münch. med. Wchnschr., Munich, 1931, LXXVIII, 949.

9. Poulsen, V., Jahrb. f. Kinderh., Berlin, 1931, CXXX, 127.

10. Symes, J. O., Erythema nodosum, Bristol, 1928.

11. Tachau, Handb. d. Haut-u. Geschlechtkrankh., 1928, VI.

12. Wallgren, A., Handb. d. Kindertuberk. v. Engel und Pirquet, Leipzig, 1930, 809.

13. Wiborg, Norsk Mag. f. Lægevidensk., Oslo, 1923, LXXXIV, 135. 